\title{
A política habitacional no Rio Grande do Sul entre os anos 1999 e 2014
}

\author{
Paulo Antônio França \\ Ricardo Letizia Garcia
}

Universidade Estadual do Rio Grande do Sul, Especialização em Gestão Pública, Porto Alegre, RS, Brasil.

E-mails: pauloasf@sehabs.rs.gov.br ricardo-garcia@uergs.edu.br

Recebido em: 21 jun. 2017. Revisado: 1 nov.2017. Aceito: 22 nov. 2017.

DOI: http://dx.doi.org/10.21674/2448-0479.42.230-245

\section{Resumo}

O artigo tem por objetivo realizar a descrição do comportamento da política habitacional no Rio Grande do Sul, considerando sua relação com a política nacional da área, verificada no período de atuação da Secretaria de Habitação e Saneamento, entre 1999 e 2014. Logo, procurou-se demonstrar que as contribuições dadas em cada gestão estadual, através das ações e investimentos em produção habitacional, não tiveram importância significativa na redução do déficit habitacional do Estado, principalmente no atendimento das pessoas das faixas de menor renda. Além disso, foi realizada também uma análise comparativa da evolução do déficit habitacional do Rio Grande do Sul com alguns outros Estados, no período entre 1995 e 2012. Os resultados indicam que a existência de uma entidade executora da política habitacional no governo não contribuiu de maneira significativa para a diminuição do déficit habitacional.

Palavras-chave: Política habitacional. Déficit habitacional. Habitação Social.

\section{Abstract \\ The housing policy in Rio Grande do Sul from 1999 and 2014}

The article aims to describe the behavior of the housing policy in Rio Grande do Sul, considering its relation with the national policy of the area, verified in the period of the Secretariat of Housing and Sanitation, between 1999 and 2014. Therefore, it was demonstrated that the contributions given in each state management through actions and investments in housing production did not have a significant importance in reducing the state's housing deficit, especially in the care of people from lower income brackets. In addition, a comparative analysis of the evolution of the housing deficit of Rio Grande do Sul and other states in the period between 1995 and 2012 was carried out. The results indicate that the existence of a government housing executing agency did not contribute in a significant way for the reduction of the housing deficit.

Keywords: Housing policy. Housing deficit. Social habitation. 


\section{Introdução}

O intenso processo de urbanização no Brasil e no RS gerou um grave desequilibrio entre oferta e demanda por habitações sem que soluções de mercado atendessem as necessidades de moradia urbana. A questão habitacional tornou-se objeto de políticas públicas, mas não foi capaz de universalizar o acesso à moradia. $\mathrm{A}$ um consenso entre os estudiosos sobre $\mathrm{o}$ assunto que a questão habitacional deve ser prioridade pública e políticas de subsídio à moradia social e popular devem ser consideradas como essenciais para a sua implantação com sucesso. A habitação incluída na lista dos direitos fundamentais de segunda geração está relacionada no artigo $6^{\circ}$ da Constituição Brasileira, referente aos direitos sociais, desde fevereiro de 2000. A partir daí passou a figurar mais frequentemente nas discussões e propostas sobre políticas públicas em todos os níveis de governo, meios acadêmicos e movimentos sociais.

A questão da habitação é um item importante para determinar a qualidade de vida e do bemestar da população, podendo ser analisada sob diversos aspectos, sendo os principais, o político, o econômico e o social. No aspecto político, a habitação serviu como instrumento ideológico e eleitoral, observado em diversos períodos da história do Brasil, como na década de 1930, quando foi utilizada como meio capaz de transformar a classe trabalhadora em defensores da propriedade, da ordem e do conservadorismo, ou na década de 1940, em que a Fundação da Casa Popular foi utilizada para fins clientelista e assistencialista, e também na época dos governos militares, em relação aos financiamentos de longo prazo, que criou na população um desejo de estabilidade social, em oposição à participação em movimentos de greve ou de protesto.

No aspecto econômico, voltamos à década de 1930, quando a habitação passa a ser vista como condição básica de reprodução da força de trabalho e como fator importante na estratégia de industrialização do país, também na década de 1960, quando da criação do Banco Nacional de Habitação - BNH, que teve como objetivo implícito movimentar os setores da construção civil e de estimular o ramo de crédito imobiliário, e mais recentemente, tivemos com programa Minha Casa Minha Vida, utilizado como um meio de gerar emprego e renda para se contrapor à crise econômica mundial de 2008. No aspecto social, a habitação está relacionada à qualidade de vida e da comunidade com um todo, no sentido de atender as condições do domicílio, referentes ao padrão construtivo, abastecimento de água, instalações sanitárias, disponibilidade de sistema viário, acesso a equipamentos urbanos - educação, saúde, lazer, etc. - elementos que dignificam a pessoa no melhor aproveitamento do espaço urbano.

Diante do exposto e entendendo que a habitação é um fator importante no estabelecimento da justiça social e na situação de bem-estar da população e que as políticas públicas não têm se mostrado efetivas no atendimento as pessoas que delas mais necessitam, se procurou fazer uma análise da política habitacional no Rio Grande do Sul e, ao mesmo tempo, fazer uma relação com a política nacional no período compreendido de 1999 a 2014, que corresponde ao intervalo entre a criação e a extinção da Secretaria de Habitação do Estado.

Como objetivos específicos buscou-se identificar como a produção de habitação de interesse social foi conduzida em cada governo para diminuir o déficit habitacional e verificar se a ausência de 
uma entidade executora das políticas habitacionais no Estado do RS reduziu a eficiência de políticas habitacionais. A partir da análise dos objetivos propostos testou-se em que medida a política habitacional atendeu as necessidades da população gaúcha nos 16 anos de atuação da Secretaria de Habitação e Saneamento (Sehabs).

Inicialmente, fez-se algumas considerações sobre políticas públicas, relacionando com as funções do Estado. Após, colou-se alguns conceitos sobre déficit habitacional. Depois, foi feito um apanhado histórico da política habitacional no Brasil e no Estado no período anterior à criação da Sehabs. A seguir explicou-se o método adotado e abordou-se a as principais ações e programas implementados no Brasil e no Estado no período analisado, bem como foi feita a comparação da evolução dos déficits habitacionais entre alguns Estados.

\section{Políticas públicas e as funções do Estado; conceitos e definições}

A política pública é considerada como uma mobilização político-administrativa para articular e alocar recursos e esforços para solucionar um dado problema coletivo e embora se constitua na unidade base de funcionamento das atividades estatais nos diferentes âmbitos, ainda é um conceito difícil de ser definido. Nesse sentido fica-se com um conceito mais abrangente, que define a política pública como "uma ampla estrutura de ideias e valores dentro da qual decisões são tomadas e a ação, ou inação, levada a efeito por governos em relação a alguma questão ou problema" (PROCOPIUCK; 2013). Quanto aos tipos de políticas públicas, temos quatro formatos: distributiva, redistributiva, regulatória e constitutiva.

As políticas distributivas atribuem vantagens a diversos grupos e aparentemente não acarretam custos aos demais. Os meios de distribuição podem ser via subsídios, em produtos e serviços e concessão de benefícios diretamente aos interessados. Sendo que as políticas redistributivas visam ao deslocamento consciente de recursos financeiros diretos ou outros valores entre camadas sociais e grupos da sociedade. São políticas que procuram mudar o grau de concentração de recursos mediante mecanismos de repasse de pontos de maior concentração para os de menor. Já as políticas regulatórias não oferecem bens ou serviços, mas sim estabelecem o controle estatal sobre a utilização de recursos ou sobre a execução de atividades por diferentes segmentos da sociedade. Finalmente, as políticas constitutivas são as que criam ou estruturam as condições para que determinados problemas passem a ser tratados sistematicamente. São utilizadas para regular as demais políticas. A seguir tem-se uma abordagem resumida do ciclo de políticas públicas que segundo diversos autores têm cinco fases: definição da agenda, definição de alternativas, tomada de decisão, implementação e avaliação.

O ciclo inicia com a definição da agenda, onde é identificado o problema que merece atenção prioritária dos gestores públicos, onde também se percebe que muitos atores relevantes estão insatisfeitos, se delimita as possíveis causas e se avalia a existência de alternativas para resolução. Na definição de alternativas se avalia as soluções disponíveis para os problemas, onde se leva em consideração a viabilidade técnica e financeira, a conformidade com valores da sociedade e a receptividade da comunidade política. Ainda na fase de tomada de decisão temos a escolha de uma das alternativas possíveis, ponderando expectativas de resultados e custos para sua obtenção, segundo os meios 
a serem empregados. Normalmente precedem ao ato de decisão, processos de conflitos e de acordos envolvendo os atores mais influentes na política e na administração.

Já na fase de implementação são desenvolvidas as regras, estruturas de regulação e linhas gerais para execução das decisões, onde pode haver mudanças nas decisões para se ajustarem às restrições operacionais e também são elaborados programas com objetivos e padrões de desempenho, incluindo cronograma de operações. Por último, ocorre a fase de avaliação, onde é emitido juízo de valor sobre os resultados a partir de parâmetros de situação esperada e grau de alcance dos resultados, previstos no planejamento; também se atribui responsabilidades em relação às discrepâncias observadas no desempenho.

Conforme Avate e Biderman (2004), relacionado as políticas públicas estão às funções do governo que, no sentido de promover o bem-estar social da população e o desenvolvimento econômico, tem três principais atribuições: função alocativa, função distributiva e função estabilizadora. A função alocativa tem o objetivo de alocar os recursos quando não for possível, pelas condições de mercado a determinação de preços de bens e serviços, de forma a assegurar uma maior eficiência na utilização dos recursos disponíveis na economia. $\mathrm{Na}$ área habitacional, essa função se aplica quando o governo concentra investimentos nas regiões onde o déficit habitacional é mais acentuado.

$\mathrm{Na}$ função distributiva, o governo necessita intervir na economia para tentar corrigir a desigualdade existente na divisão da renda nacional, visto que esta divisão normalmente não é igualitária, sendo que a intervenção pode se dar por meio de transferências, impostos e subsídios. Com os programas habitacionais o governo se utiliza desta função para distribuir subsídios para beneficiar famílias de baixa renda. Já na função estabilizadora, o objetivo principal da intervenção do governo é controlar a demanda agregada, através, por exemplo, do controle dos gastos públicos e do crédito e do aumento da tributação, de forma que o impacto causado pelas crises inflacionárias ou de recessão econômica seja atenuado. Como exemplo, com os elevados gastos do governo na construção de unidades habitacionais de interesse social, elevaram-se também o nível de emprego e a renda da economia.

\section{Déficit habitacional}

O déficit habitacional é o indicador que calcula a necessidade de reposição do estoque de moradias existentes, bem como a necessidade de incrementar o estoque de moradias e tem o objetivo de orientar os agentes públicos responsáveis pela política habitacional e a elaboração dos diversos programas que sejam capazes de suprir essas necessidades nas esferas de governo dos Municípios, Estados e União (FUNDAÇÃO JOÃO PINHEIRO, 2014). O trabalho mais utilizado no Brasil é o estudo desenvolvido pela Fundação João Pinheiro, iniciado em 1995 e que estabeleceu um conjunto de indicações metodológicas que vem sendo atualizado e revisado sucessivamente, e tem sido adotado como referência no país, principalmente pelo Ministério das Cidades.

O déficit habitacional está ligado diretamente às deficiências do estoque de moradias, é o chamado déficit quantitativo, que tem dois componentes: déficit por reposição de estoque e déficit por incremento de estoque. $O$ déficit por reposição de estoque está relacionado aos domicílios rústicos e à depreciação. Os domicílios rústicos são os que não apresentam paredes de alvenaria ou de madei- 
ra aparelhada, sendo que a depreciação está relacionada à vida útil do imóvel, que no caso é tomada como 50 anos de construção. O déficit por incremento de estoque inclui os domicílios improvisados, a coabitação familiar e o ônus excessivo com aluguel. Os domicílios improvisados são todos os locais destinados a fins não residenciais que sirvam de moradia e o item coabitação familiar compreende as famílias conviventes secundárias que vivem junto a outra família em um mesmo domicilio e das que vivem em cômodos cedidos ou alugados. Outro conceito se refere ao déficit habitacional qualitativo, que não implica necessariamente a construção de novas habitações, que são os domicílios que tem densidade excessiva de moradores por dormitório, os que tem carência de serviços de infraestrutura energia elétrica, abastecimento de água, esgotamento sanitário, coleta de lixo - e os que apresentam inadequação fundiária urbana.

\section{Antecedentes da política habitacional no Brasil e no RS}

As primeiras experiências de produção habitacional pública no Brasil, que foram os Institutos de Aposentadoria e Pensões (IAPs) faziam parte do arranjo institucional corporativo estruturado na década de 1930 no primeiro governo Vargas. Os IAPs estavam ligados aos sindicatos de profissões regulamentadas pelo Ministério do Trabalho, que tinha como uma das formas de investimentos dos recursos administrados por estes, era o financiamento habitacional, sendo que neste arranjo, teoricamente só tinham acesso aos financiamentos os que fossem associados a algum sindicato.

No Rio Grande do Sul, o maior exemplo da atuação dos IAPs, foi a vila operária do IAPI, no bairro Passo D'Areia em Porto Alegre, pelo Instituto de Aposentadoria e Pensões dos Industriários, no período de 1944 a 1954. Este conjunto residencial era composto de 700 edificações, entre casas isoladas, geminadas, de duas a duas e edifícios de habitações coletivas com 2, 3 e 4 pavimentos, totalizando 2.533 habitações. Fazem parte do conjunto diversas áreas verdes, bem como núcleos comerciais e de serviços, além de infraestrutura em equipamentos comunitários.

Instituída em 1946, a Fundação da Casa Popular foi o primeiro órgão, de âmbito nacional, voltado exclusivamente para produção habitacional de baixa renda. Elaborada com o intuito de superar o corporativismo e o clientelismo que marcou a atuação dos IAPs, a FCP, apesar de sua fragilidade financeira sobreviveu até 1964 , sendo considerada um símbolo da ineficiência governamental e do predomínio do fisiologismo em detrimento ao interesse público. Em seus dezoito anos de funcionamento a FCP produziu 18.132 unidades habitacionais, sendo que os IAPs, de 1937 a 1964, produziram através de seus programas sociais, 123.995 unidades habitacionais. Já no Rio Grande do Sul, foram construídas 613 casas em 13 conjuntos habitacionais, revelando o desempenho pouco expressivo da FCP no período.

A partir de 1964 com a criação do Banco Nacional da Habitação e a instituição do Sistema Federal de Habitação, que se propunha a ser um sistema de produção habitacional que se autofinanciasse, mantendo assim o princípio da auto sustentação financeira da atividade, foi decomposto em dois subsistemas, baseado nas suas fontes de recursos: o Sistema Brasileiro de Poupança e Empréstimo (SBPE) e o BNH-FGTS. O primeiro subsistema, SBPE, composto pela poupança voluntária mobilizada pela Caixa Econômica Federal, Caixas Econômicas Estaduais e bancos privados, destinouse ao financiamento da produção habitacional realizada pela incorporação imobiliária. Já o segundo 
subsistema, tinha como fonte de recursos o FGTS, constituído por contribuições compulsórias no valor de $8 \%$ dos salários da economia formal, gerenciado pelo $\mathrm{BNH}$, voltado à produção de habitação de interesse social. Com base no baixo desempenho social, alto nível de inadimplência, baixa liquidez do sistema e movimentos de mutuários organizados nacionalmente, o BNH foi extinto em 1986 pelo governo da Nova República, tendo produzido no período cerca de 4,4 milhões de habitações.

No período que vai da extinção do BNH ao primeiro governo de Fernando Henrique Cardoso (1995-1998), as principais ações na área habitacional foram as seguintes: as atribuições do BNH foram transferidas para a Caixa Econômica Federal; as políticas de habitação passaram por diversos órgãos desde o Ministério do Desenvolvimento Urbano e Meio Ambiente em 1985 até chegar ao Ministério do Planejamento e Orçamento, em 1995, através da Secretaria de Política Urbana; o governo Sarney instituiu o Programa Nacional de Mutirões Comunitários unificando os programas alternativos Profilurb, Pró-Morar e João-de-Barro; o governo Collor (1990-1992) criou o Plano de Ação Imediata para Habitação, que se propunha a construir 245 mil unidades habitacionais em 180 dias; no governo Itamar Franco (1992-1994) foram criados os programas Habitar-Brasil e Pró- Moradia e também instituídos os conselhos de participação comunitária e finalmente no primeiro governo FHC (1995-1998) tivemos o Programa Brasileiro de Qualidade e Produtividade Habitacional e o Programa Carta de Crédito-FGTS, destinado à população de renda familiar entre 3 e 12 salários mínimos.

No Rio Grande do Sul no período pós-64 até 1995 tivemos a atuação da Companhia de Habitação-RS, que foi criada para ser o agente financeiro e promotor da política nacional, sendo responsável pela operação dos programas estabelecidos nacionalmente e pela administração dos créditos do SFH, concedidos ás populações de baixa renda.

Durante o período de existência do BNH a Cohab-RS, foi o principal agente executor da política nacional, fixada de forma centralizada pelo mesmo, sendo que alguns dos programas implantados foram o Programa de Financiamento de Lotes Urbanizados - Profilurb em 1975; o Programa de Financiamento da Construção ou Melhoria da Habitação de Interesse Social - Ficam em 1977 e o Programa de Erradicação da Sub-Habitação - Promorar em 1979. Com o fim do BNH, até a sua extinção em 1995, a Cohab-RS passa a atuar com iniciativas orçamentárias do governo Estadual, através de dois programas, o Programa Lotes Urbanizados - Prolurb e o Programa de Habitação, Segurança e Saúde - PHS, sendo produzidas no período cerca de 9.500 unidades habitacionais.

Desde sua criação até 1995, quando inicia seu processo de liquidação, a Cohab-RS viabilizou a execução de cerca de 100 mil unidades habitacionais, sendo que a distribuição dos investimentos, principalmente no período do $\mathrm{BNH}$, não se deu em função do atendimento pleno das necessidades habitacionais localizadas, mas sim com a construção de grandes conjuntos, resultando muitas vezes em deslocamento populacional. Após a extinção da Cohab-RS, a questão habitacional ficou vinculada ao Departamento de Habitação - Dehab, da Secretaria de Obras Públicas, Saneamento e Habitação, sendo neste período criado o Sistema Estadual de Habitação de Interesse Social em 1995. Quanto à atuação do Dehab, ficou restrito a articular os programas federais da época, o Pró-Moradia, em que recursos do FGTS eram repassados como empréstimos aos municípios, e o Habitar-Brasil, que repassava os recursos provenientes do Orçamento Geral da União para o Estado, que o transferia aos 
municípios mediante convênio. De 1995 a 1998, foram conveniados empreendimentos que resultaram em cerca de 3.900 unidades habitacionais.

\section{Materiais e Métodos}

A pesquisa foi descritiva onde se fez uma análise minuciosa e descritiva da política habitacional no RS, investindo-se na coleta e no levantamento de dados do problema de pesquisa. Utilizouse de quadros e tabelas para análise estatística dos dados coletados. O estudo também fez uma revisão teórica a partir de uma análise da Lei Orçamentária Anual do Estado, junto à Secretaria de Planejamento - RS, ano a ano, nos quatro governos do período considerado, 1999-2014 (intervalo de atuação da Secretaria de Habitação na implementação das políticas habitacionais no Estado). Por meio de uma abordagem quantitativa foi analisado quanto do orçamento total da administração direta foi aplicado na Secretaria de Habitação, para ver percentualmente a evolução dos valores direcionados à política habitacional do Estado do Rio Grande do Sul.

Com base em levantamento no sistema de controle do Departamento de Produção e Programas Habitacionais da Sehabs - RS se coletou dados de 1999-2014. Se fez uma análise dos valores aplicados em cada governo diretamente na produção de unidades habitacionais (considerando as casas com aproximadamente $40,0 \mathrm{~m}^{2}$ ) e lotes urbanizados (considerando os lotes com área média de 200,0 $\mathrm{m}^{2}$ e infraestrutura básica prevista na Lei de Parcelamento do Solo Urbano), para verificar a contribuição de cada para a diminuição do déficit habitacional no Estado Rio Grande do Sul. A partir de levantamentos feitos sobre o déficit habitacional no Brasil, pela Fundação João Pinheiro - MG o estudo também buscou dados no período considerado de 1995-2012, para analisar a evolução do déficit habitacional de alguns Estados que possuem entidade executora da política habitacional do governo estadual, para comparar com o déficit verificado no Estado do Rio Grande do Sul.

\section{Resultados e Discussão}

\section{A política habitacional entre os anos de 1999-2014}

No segundo governo FHC (1999-2002) foram criados dois programas: o Programa de Arrendamento Residencial - PAR, em 1999, que tem por objetivo propiciar moradia à população de baixa renda, através de arrendamento residencial com opção de compra e o Programa de Subsídio à Habitação de Interesse Social - PSH, em 2002, que teve por objetivo oferecer acesso à moradia digna para cidadãos de baixa renda por intermédio da concessão de subsídios, sendo os recursos distribuídos de acordo com o déficit habitacional da cada região do país. Um fato importante ocorrido neste período foi a aprovação do Estatuto da Cidade, em julho de 2001, que possibilitou valer a função social da propriedade, constituindo um marco importante para a busca da solução do problema habitacional brasileiro. No Rio Grande do Sul, com a criação da Secretaria Especial de Habitação - Sehab, em maio de 1999, o Estado passa novamente a investir recursos orçamentários em programas que 
conferem maior protagonismo aos municípios, com operações realizadas em parceria com prefeituras e com cooperativas habitacionais.

A Sehab se estruturou em três departamentos técnicos: o Departamento de Produção - Depro, que tem a função de formular, coordenar e fiscalizar os programas de produção de unidades habitacionais e lotes urbanizados; o Departamento de Reassentamentos e Regularização Fundiária Derer, que tem a função desenvolver ações de regularização fundiária, reassentamentos, serviços de topografia, levantamento socioeconômico, levantamento cadastral, execução de serviços de infraestrutura, estudos de viabilidade urbanística, etc.; e Departamento de Fomento ao Cooperativismo - Decoop, que tinha o objetivo de coordenar os projetos desenvolvidos pelas cooperativas habitacionais, além de oferecer formação educacional de seus quadros associativos, também ficou vinculada à Sehab a Cohab em processo de liquidação, com a função da regularização fundiária dos conjuntos produzidos e administração da carteira de créditos.

O principal programa implementado pela Sehab, foi o Moradia Popular, criado em 1999, sendo destinado às famílias com renda de até cinco salários mínimos, para a produção de empreendimentos habitacionais - casas, módulos sanitários, lotes urbanizados e melhorias habitacionais -, com a participação dos municípios e uma contrapartida mínima de $50 \%$ dos investimentos que eram decididos no Orçamento Participativo.

Quadro 1 - Governo Olívio Dutra (1999-2002) - Relação orçamento da administração direta, orçamento da Sehab e produção habitacional

\begin{tabular}{|c|c|c|c|c|c|}
\hline Ano & $\begin{array}{c}\text { Orçamento Total Adm. } \\
\text { Direta }(\mathrm{R} \$)^{*}\end{array}$ & $\begin{array}{l}\text { Orçamento } \\
\text { Sehab }(R \$)^{*}\end{array}$ & $\%$ & $\begin{array}{c}\text { Produção Unid. Hab. } \\
\text { e Lotes Urban. }\end{array}$ & $\begin{array}{c}\text { Valores Aplicados Prod. } \\
\text { Habitacional }(\mathrm{R} \$)^{*}\end{array}$ \\
\hline 1999 & 22.217 .870 .638 & 99.949 .072 & 0,4029 & 8.048 & 48.351 .769 \\
\hline 2000 & 23.713.326.593 & 24.737 .770 & 0,1043 & 2.190 & 7.284.722 \\
\hline 2001 & 24.353 .020 .505 & 38.479 .625 & 0,1580 & 1.466 & 8.912 .139 \\
\hline 2002 & 21.949.401.057 & 39.777 .345 & 0,1812 & 5.552 & 18.687.717 \\
\hline \multicolumn{2}{|r|}{ Totais } & 202.943 .812 & & 17.296 & 83.236 .347 \\
\hline
\end{tabular}

Fonte: Secretaria de Orçamento, Gestão e Participação Cidadã-RS e Secretaria de Habitação e Saneamento-RS. *Valores atualizados pelo IPCA-IBGE base Jan-2015

A análise do quadro 1, governo Olívio Dutra, na parte financeira, mostra que os valores destinados à Sehab foram significativos em relação ao orçamento do Estado somente no primeiro ano do período em questão, decaindo bastante no ano seguinte e voltando a crescer nos dois últimos anos. Quanto aos valores aplicados diretamente na produção habitacional, somente se destacam, primeiro e quarto anos do período analisado, com respectivamente $49 \%$ e $47 \%$ do orçamento total da Sehab. Com relação às unidades habitacionais e lotes urbanizados produzidos, a quantidade verificada no período equivale a $8,39 \%$ do déficit habitacional calculado pela Fundação João Pinheiro para o ano de 2000.

O primeiro governo Lula (2003-2006) teve como principal ação a criação do Ministério das Cidades, estruturado com a Secretaria Nacional de Habitação, a Secretaria Nacional de Programas Urbanos, a Secretaria Nacional de Saneamento Ambiental e a Secretaria de Transporte e Mobilidade Urbana. O Ministério teve como objetivo integrar as políticas ligadas às cidades, articular e qualificar os diferentes entes federativos na montagem de uma estratégia nacional, para encontrar soluções para os problemas urbanos. Em outubro de 2003, foi realizada a I Conferência Nacional das Cidades 
e foi criado o Conselho das Cidades, com a finalidade de assessorar, estudar e propor diretrizes para a execução da Política Urbana Nacional. Em 2004 o governo federal lançou a Política Nacional de Habitação - PNH, cuja finalidade era orientar as ações dos órgãos e entidades dos diferentes níveis de governo na área habitacional, em uma ação compartilhada com o setor privado, de modo a garantir à população brasileira o acesso à moradia adequada, com urbanização e integração à cidade, principalmente para a população de baixa renda.

Outro fato importante no período foi o significativo aumento dos recursos do FGTS para financiamentos habitacionais, o que permitiu a criação da Resolução 460 do Conselho Curador do FGTS, que trata da aplicação massiva de recursos em subsídios para habitação de interesse social. No RS, a partir do governo Rigotto (2003-2006) a Sehab passou a se chamar Secretaria de Habitação de Desenvolvimento Urbano - Sehadur, vinculando a Fundação Estadual de Planejamento Metropolitano e Regional - Metroplan, entidade que tem por objetivo de promover o desenvolvimento integrado entre os municípios. Também nesse período foi criado o Conselho Estadual das Cidades, para atender as diretrizes estabelecidas pelo Ministério das Cidades.

Em 2003 foi instituído o programa Minha Casa, contendo as mesmas características do programa Moradia Popular, ou seja, promoção da política habitacional com inclusão social, colocando o cidadão e sua família como centro de políticas públicas integradas, visando à qualificação social. Outras iniciativas do período foram a criação da Câmara Setorial de Regularização Fundiária, o Programa Estadual de Habitação Indígena, cujo objetivo era de combater o déficit habitacional indígena das tribos Kaingang e Guarani, respeitando s exigências culturais, e o Programa Cheque Casa, contendo objetivos semelhantes aos do Minha Casa, diferindo apenas na forma de execução, que se concretiza através da disponibilização de crédito direto à clientela identificada.

Quadro 2 - Governo Germano Rigotto (2003-2006) - Relação orçamento da administração direta, orçamento da Sehadur e produção habitacional

\begin{tabular}{|c|c|c|c|c|c|}
\hline Ano & $\begin{array}{c}\text { Orçamento Total } \\
\text { Adm. Direta (R\$) }\end{array}$ & $\begin{array}{c}\text { Orçamento } \\
\text { Sehadur (R\$)* }\end{array}$ & $\%$ & $\begin{array}{c}\text { Produção Unid. Hab. e } \\
\text { Lotes Urban. }\end{array}$ & $\begin{array}{c}\text { Valores Aplicados Prod. } \\
\text { Habitacional }(\mathrm{R} \$)^{*}\end{array}$ \\
\hline 2003 & 20.128 .044 .725 & 46.173 .583 & 0,2294 & 855 & 4.033 .826 \\
\hline 2004 & 22.080 .579 .808 & 56.007 .487 & 0,2536 & 3.089 & 14.427 .015 \\
\hline 2005 & 23.321 .235 .786 & 54.149 .860 & 0,2322 & 615 & 8.694 .326 \\
\hline 2006 & 25.543 .949 .611 & 43.130 .241 & 0,1686 & 1.598 & 5.583 .649 \\
\hline Totais & 199.461 .171 & & 6.107 & 32.738 .816 & \multicolumn{2}{|c}{} \\
\cline { 1 - 3 } & & &
\end{tabular}

Fonte: Secretaria de Orçamento, Gestão e Participação Cidadã-RS e Secretaria de Habitação e Saneamento-RS. Valores atualizados pelo IPCA-IBGE base Jan-2015

A análise do Quadro 2, governo Germano Rigotto, mostra que na parte financeira os valores destinados à Sehadur, em relação ao orçamento do Estado, mantiveram-se estáveis nos três primeiros anos do período, decaindo no último ano. Com relação aos valores aplicados diretamente na produção habitacional, somente se destaca o segundo ano do período analisado com cerca de $26 \%$ do orçamento total da Sehadur, devido aos significativos recursos aplicados em melhorias habitacionais. No que se refere às unidades habitacionais e aos lotes urbanizados produzidos, a quantidade verificada no período equivale a $2,2 \%$ do déficit habitacional calculado pela Fundação João Pinheiro no ano de 2005. 
No segundo governo Lula (2007-2010), inicialmente foi criado o Programa de Aceleração do Crescimento - PAC, com iniciativas no setor habitacional e no saneamento, pois além de destinar recursos para obras de infraestrutura para produção, dirigiu aplicações para urbanização de assentamentos precários, tendo destinado onze bilhões de reais para atendimento das camadas mais pobres, com construção de moradias e urbanização de favelas. Porém, houve uma demora para se perceber de forma significativa o crescimento habitacional.

O principal programa habitacional do período, foi lançado em 2009, com o nome de Minha Casa, Minha Vida - MCMV. O objetivo principal foi reaquecer o mercado imobiliário no Brasil, responder à crise mundial de 2008, e financiar diretamente empresas e construtoras para a construção de habitações para as classes com faixa de renda de 0 a 10 salários mínimos. Com a meta de construir um milhão de unidades habitacionais, sendo 400 mil destinadas às famílias com rendimentos mensais de até três salários mínimos, o programa MCMV trouxe a política habitacional como uma das principais prioridades do governo, que usou instrumentos da política fiscal para alocar recursos em setores que interessava ao Estado e distribuir renda através de transferências e descontos, gerando assim mais emprego e renda.

Nesse período, no plano estadual do governo Yeda (2007-2010) foi alterada a estrutura da Sehadur, com a inclusão da área de saneamento, através da incorporação do Departamento de Saneamento - Desan e a vinculação da Companhia Riograndense de Saneamento - Corsan, com objetivo de facilitar o acesso aos recursos disponibilizados no âmbito federal, através do Ministério das Cidades. Ainda no período foi instituído o Sistema Estadual de Habitação de Interesse Social - Sehis, o Fundo Estadual de Habitação de Interesse Social - Fehis e o Conselho Gestor do Fehis, adequando o sistema estadual à legislação federal, através da vinculação do Conselho Estadual das Cidades ao sistema.

Os principais programas habitacionais implantados no período foram Nossas Cidades e Emancipar, o primeiro com as mesmas características dos anteriores Moradia Popular e Minha Casa e, o segundo, com ação integrada de várias secretarias partiu da concepção da habitabilidade, na qual a habitação não se restringe à casa, mas incorpora também o direito à legalização fundiária, infraestrutura, saneamento, mobilidade e transporte coletivo e serviços urbanos e sociais.

Quadro 3- Governo Yeda Crusius (2007-2010) - Relação orçamento da administração direta, orçamento da Sehadur e produção habitacional

\begin{tabular}{|l|c|c|c|c|c|}
\hline \multicolumn{1}{|c|}{ Ano } & $\begin{array}{c}\text { Orçamento Total } \\
\text { Adm. Direta(R\$) }\end{array}$ & $\begin{array}{c}\text { Orçamento } \\
\text { Sehadur(R\$) }\end{array}$ & $\%$ & $\begin{array}{c}\text { Produção Unid. Hab. e } \\
\text { Lotes Urban. }\end{array}$ & $\begin{array}{c}\text { Valores Aplicados } \\
\text { Prod. Habitacional(R\$) }\end{array}$ \\
\hline 2007 & 25.917 .985 .421 & 31.084 .273 & 0,1199 & 329 & 742.557 \\
\hline 2008 & 26.947 .901 .422 & 145.712 .249 & 0,5407 & 4.432 & 14.215 .211 \\
\hline 2009 & 28.914 .696 .280 & 158.789 .786 & 0,5491 & 3.802 & 20.196 .163 \\
\hline 2010 & 31.191 .795 .207 & 169.892 .399 & 0,5447 & 10.220 & 63.507 .387 \\
\hline Totais & 505.478 .707 & & 18.783 & 98.661 .318 & \multicolumn{1}{|c|}{} \\
\cline { 1 - 4 } & & &
\end{tabular}

Fonte: Secretaria de Orçamento, Gestão e Participação Cidadã-RS e Secretaria de Habitação e Saneamento-RS. Valores atualizados pelo IPCA-IBGE base Jan-2015.

$\mathrm{Na}$ análise do quadro 3, governo Yeda Crusius, observa-se um aumento significativo de valores destinados à Sehadur em relação ao orçamento do Estado nos três últimos anos do período, devido aos recursos aplicados na área de saneamento. Entretanto, no caso dos valores aplicados diretamente na produção habitacional, somente no quarto ano do período em questão houve destaque, 
quando chegou a cerca de $37 \%$ do orçamento total da Sehadur, devido a grande quantidade de convênios de complementação do programa Minha Casa, Minha Vida. Quanto às unidades habitacionais produzidas, a quantidade verificada no período equivale a $8,3 \%$ do déficit habitacional calculado pela Fundação João Pinheiro para o ano de 2008.

A política habitacional no primeiro governo Dilma (2011-2014) não sofreu alteração em relação ao período anterior, sendo a novidade o início da segunda fase do programa Minha Casa, Minha Vida, que, em três anos, objetivou construir dois milhões de unidades habitacionais. Nesta nova versão, o MCMV reajustou as faixas de renda elegíveis, destinou $60 \%$ das unidades habitacionais para a faixa de renda de até $R \$ 1.600,00$, alterou as especificações técnicas no sentido de melhorar a qualidade das moradias e incentivou as grandes empresas em atuar no escopo do programa. Outra novidade no programa MVMV II, está ligada à entrada do Banco do Brasil, na qualidade de co-gestor operacional ao lado da Caixa Econômica Federal, visando dar mais dinamismo aos processos de contratação, medição de obras, assinatura de financiamentos e repasses bancários.

Nessa época no Estado do RS, o governo Tarso Genro (2011-2014) alterou novamente a estrutura organizacional do poder executivo, e a Sehadur passou a ser denominada de Secretaria de Habitação e Saneamento - Sehabs, permanecendo com as mesmas atribuições, ou seja, coordenação e execução da política de habitação de interesse social, de desenvolvimento urbano, de regularização fundiária, reassentamento das famílias em situação de risco e os programas e obras públicas na área de saneamento básico. Também foi concluído no período o Plano Estadual de Habitação de Interesse Social.

Nesse momento a prioridade da Sehabs foi o atendimento às famílias com renda entre zero e três salários mínimos, objetivando contratar a produção de ações habitacionais urbanas e rurais, com municípios e cooperativas diretamente ou complementando programas da União. Nesse sentido, o programa Produção de Ações Habitacionais realizou contratos e convênios de complementação do programa Minha Casa, Minha Vida Nacional de Habitação Rural e MCMV - Sub 50. Outra iniciativa importante foi o lançamento do Banco de Terras, em 2011, o primeiro do país, que está sendo composto por áreas públicas ou a serem adquiridas pelo Estado, em zonas urbanas, que serão utilizadas para a construção de habitações de interesse social, beneficiando a população que recebe de zero a três salários mínimos.

Quadro 4 - Governo Tarso Genro (2011-2014) - Relação orçamento da administração direta, orçamento da Sehabs e produção habitacional

\begin{tabular}{|c|c|c|c|c|c|}
\hline Ano & $\begin{array}{l}\text { Orçamento Total } \\
\text { Adm. Direta }(\mathrm{R} \$)^{*}\end{array}$ & $\begin{array}{l}\text { Orçamento } \\
\text { Sehabs }(\mathrm{R} \$)^{*}\end{array}$ & $\%$ & $\begin{array}{l}\text { Produção Unid. Hab. e } \\
\text { Lotes Urban. }\end{array}$ & $\begin{array}{l}\text { Valores Aplicados Prod. } \\
\text { Habitaciona I(R\$) }\end{array}$ \\
\hline 2011 & 30.998 .922 .111 & 253.427 .098 & 0,8175 & 812 & 5.247 .441 \\
\hline 2012 & 33.126 .428 .322 & 125.022 .654 & 0,3774 & 2.811 & 11.974 .577 \\
\hline 2013 & 35.790 .373 .820 & 318.943 .486 & 0,8911 & 3.040 & 11.225 .737 \\
\hline 2014 & 37.113 .396 .356 & 172.853 .044 & 0,4657 & 4.874 & 21.231 .382 \\
\hline Totais & 870.246 .282 & & 11.537 & 49.679 .137 & \\
\hline
\end{tabular}

Fonte: Secretaria de Orçamento, Gestão e Participação Cidadã-RS e Secretaria de Habitação e Saneamento-RS. Valores atualizados pelo IPCA-IBGE base Jan-2015

$\mathrm{Na}$ análise do quadro 4, governo Tarso Genro, verifica-se um aumento significativo no primeiro e terceiro ano dos valores destinados a Sehabs em relação ao orçamento do Estado, também de- 
vido a aumentos importantes de recursos aplicados na área de saneamento. Quanto aos valores aplicados diretamente na produção habitacional, destaca-se o quarto ano do período analisado, mesmo assim representando somente $12,3 \%$ do orçamento total da Sehabs. Já nas unidades habitacionais produzidas a quantidade verificada no período equivale a $6,3 \%$ do déficit habitacional calculado pela Fundação João Pinheiro para o ano de 2012.

Resumindo, com uma produção habitacional de 53.723 no período analisado, 1999-2014, incluindo unidades habitacionais e lotes urbanizados, a maior contribuição ocorreu no governo Yeda Crusius, com cerca de $35 \%$ do total. Sendo que, no período, o déficit habitacional passou, em unidades habitacionais, de 212.887 em 2000 para 182.624 em 2012, havendo redução de 16,5 \% em termos absolutos e de 42,0 \% em termos relativos. Assim, embora a contribuição da política habitacional do Estado no período analisado, representar mais de 29,0 \% do déficit calculado para o ano de 2012, não é possível afirmar que a redução significativa em termos relativos do mesmo tenha relação com a intervenção do Estado na área, principalmente porque houve importantes investimentos do governo federal juntamente com os municípios, principalmente após a criação do programa Minha Casa, Minha Vida.

\section{Evolução do déficit habitacional e comparação entre os Estados}

A análise leva em consideração os Estados que tem entidades que executam a política habitacional dos mesmos, para verificar se em comparação com o Rio Grande do Sul, a extinção da Cohab-RS em 1995 teve uma importância significativa na produção de habitações e consequente redução do déficit habitacional. Assim, escolhemos cinco Estados que possuem companhias habitacionais em suas estruturas do poder executivo: Minas Gerais, Paraná, Pernambuco, Rio de Janeiro e São Paulo. O critério utilizado para a escolha dos Estados mencionados acima, que com exceção da Bahia, que não tem companhia habitacional, foi a população.

O Estado de Minas Gerais tem a Companhia de Habitação do Estado de Minas Gerais - Cohab Minas, que foi criada em $1965 \mathrm{com}$ a finalidade de combater o déficit habitacional e urbanizar vilas e favelas do Estado, sendo que toda a sua existência investiu mais de 1,5 bilhão de reais e construiu cerca de 113 mil moradias em 370 municípios mineiros. O Estado do Paraná tem a Companhia de Habitação do Paraná - Cohapar, empresa de economia mista, fundada em 1965, que atua na execução dos programas habitacionais do governo do Estado, no sentido de melhorar as condições de vida do cidadão paranaense através da moradia digna, sendo que desde a sua criação até 2010 produziu cerca de 190 mil moradias.

No Estado de Pernambuco a execução da política habitacional é feita pela Companhia Estadual de Habitação e Obras - Cehab que tem como objetivo promover a qualidade de moradia, desenvolvendo projetos de urbanização para comunidades carentes, regularização fundiária e implantado programas e projetos habitacionais com o intuito de facilitar o acesso a casa própria. Já no Estado do Rio de Janeiro, a Companhia Estadual de Habitação - CEHAB, criada em 1962, é a entidade da administração indireta vinculada à Secretaria de Estado de Habitação, que tem a atribuição de executar a política habitacional, tendo como objetivo principal o planejamento setorial, produção e comerciali- 
zação de unidades habitacionais de interesse social obedecido os critérios e normas estabelecidos pelo governo do Estado e pela legislação federal.

E por fim no Estado de São Paulo, tem a Companhia de Desenvolvimento Habitacional e Urbano, criada em 1949. É a maior agente promotora de moradia popular do Brasil, cuja finalidade é executar os programas habitacionais em todo o território do Estado, com atendimento exclusivo da população de baixa renda. A empresa está vinculada à Secretaria de Habitação do Estado e desde que iniciou suas atividades produziu e comercializou cerca de 497 mil novas unidades habitacionais.

Quadro 5 - Déficit habitacional em alguns Estados e no Brasil

\begin{tabular}{|l|c|c|c|c|c|c|c|c|c|c|}
\hline \multicolumn{1}{|c|}{ Ano } & \multicolumn{2}{|c|}{1995} & \multicolumn{2}{c|}{$\mathbf{2 0 0 0}$} & \multicolumn{2}{c|}{$\mathbf{2 0 0 5}$} & \multicolumn{2}{c|}{$\mathbf{2 0 0 8}$} & \multicolumn{2}{c|}{$\mathbf{2 0 1 2}$} \\
\hline Estado & Abs. & Rel.\% & Abs. & Rel.\% & Abs. & Rel.\% & Abs. & Rel.\% & Abs. & Rel.\% \\
\hline Minas Gerais & 382.584 & 9,1 & 511.386 & 10,4 & 525.349 & 9,3 & 474.427 & 7,8 & 464.881 & 7,1 \\
\hline Paraná & 188.937 & 8,2 & 207.273 & 7,8 & 243.126 & 7,8 & 213.157 & 6,3 & 217.701 & 6,1 \\
\hline Pernambuco & 277.704 & 15,7 & 304.052 & 15,4 & 336.797 & 14,8 & 263.958 & 10,6 & 232.071 & 8,3 \\
\hline Rio de Janeiro & 331.674 & 8,6 & 371.654 & 8,7 & 472.560 & 9,6 & 426.518 & 8,1 & 396.060 & 7,0 \\
\hline Rio G. do Sul & 212.887 & 7,6 & 206.130 & 6,8 & 277.071 & 8,1 & 226.966 & 6,2 & 182.624 & 4,8 \\
\hline São Paulo & 799.965 & 8,8 & 854.923 & 8,3 & 1.274 .245 & 10,7 & 1.060 .499 & 8,2 & 1.113 .673 & 7,9 \\
\hline Brasil & 5.083 .320 & 13,0 & 5.875 .426 & 13,1 & 6.307 .253 & 11,9 & 5.546 .310 & 9,6 & 5.244 .525 & 8,5 \\
\hline
\end{tabular}

Ao analisar-se o quadro 5, foi considerado como período inicial o ano de 1995, quando foi extinta a Cohab-RS. No Estado de Minas Gerais, no período entre 1995 a 2012, houve aumento do déficit habitacional de 21,5\% em termos absolutos e redução de $28,1 \%$ em termos relativos; no Estado do Paraná houve aumento de 15,2 \% em termos absolutos e diminuição de 34,4\% em termos relativos; no Estado de Pernambuco houve diminuição de 19,6 \% em termos absolutos e redução de 47,1 \% em termos relativos; no Estado do Rio de Janeiro houve aumento de 19,4 \% em termos absolutos e redução de 22,8 \% em termos relativos; no Estado do Rio Grande do Sul houve redução de $16,5 \%$ em termos absolutos e redução de 42,0 \% em termos relativos e no Estado de São Paulo houve aumento de 39,2 \% em termos absolutos e de redução de 34,6 \% em termos relativos. Assim dos Estados comparados, que possuem entidade executora de política habitacional, implementada pelos governos estaduais, todos apresentaram reduções em termos relativos do déficit habitacional, sendo que os que mais se destacaram foram Paraná e São Paulo, além do Rio Grande do Sul, que teve a maior redução. Em termos absolutos somente os Estados de Pernambuco e o Rio Grande do Sul apresentaram redução do déficit habitacional. Resumindo, a presença ou não de uma entidade responsável pela produção de unidades habitacionais de interesse social no Estado não influenciou de maneira importante a diminuição do déficit habitacional no período considerado, já que o Estado do Rio Grande do Sul juntamente com o Estado de Pernambuco, foram os únicos que apresentaram reduções significativas tanto em termos absolutos como em termos relativos. Quanto à redução do déficit habitacional em termos relativos e absolutos, em quase todos os Estados analisados, com exceção de São Paulo, no período entre 2008-2012, deve-se principalmente aos investimentos realizados pelo programa Minha Casa Minha Vida, instituído a partir de 2009. 


\section{Conclusão}

Entendendo que os problemas habitacionais estão relacionados ao funcionamento do mercado imobiliário, à má gestão da ocupação do solo, aos problemas legais, institucionais, à carência de infraestrutura adequada, à pobreza e a diversas situações recorrentes nas cidades brasileiras, cada vez mais é necessário que essas questões tenham um tratamento prioritário e diferenciado quando da elaboração das políticas públicas sociais.

No Brasil e Rio Grande do Sul, a habitação de interesse social esteve sempre ligada a interesses políticos, ideológicos e econômicos da classe dominante. Nesse sentido, a ação do poder público, deve entender que construir habitações significa não só unidades novas em conjuntos habitacionais, mas abrange sentido mais amplo e completo, com acesso à moradia com infraestrutura e serviços básicos, concebida de múltiplas formas - autoconstrução, mutirão, reforma, aluguel, lotes urbanizados, urbanização de favelas, além da melhora da qualidade e tecnologia construtiva convencionais.

Assim, a contribuição dada pelos governos de diferentes ideologias, na área habitacional, no Estado do Rio Grande do Sul, se não conseguiram implementar políticas que garantissem o equilíbrio na distribuição dos recursos tanto a nível de regiões, como no atendimento das camadas de renda mais baixa da população, houve avanços significativos, já que em termos relativos, o Estado apresentou o menor déficit habitacional dentre todos da federação, no cálculo feito pela Fundação João Pinheiro para o ano de 2012, que foi de $4,8 \%$.

Espera-se que no Estado seja alcançado num futuro breve os objetivos de todas as políticas de habitação, ou seja, viabilizar o acesso à terra urbanizada e à habitação urbana e rural digna e sustentável para a população de baixa renda, de modo a ajudar o desenvolvimento econômico e o bemestar pleno da população do país.

\section{Referências}

AGUIAR, M. H. de. O Fundo Nacional de Habitação de Interesse Social: avanços e limites na perspectiva da reforma urbana. Dissertação (Mestrado em Planejamento Urbano e Regional). Universidade Federal do Rio de Janeiro. Rio de Janeiro, 2008.

ANDRADE, E. S. J. Síntese histórica das políticas habitacionais no Brasil (1964 a 2010): avanços de antigas propostas e retorno a velhas práticas. XIV ENCONTRO NACIONAL DA ANPUR. Rio de Janeiro, 2010.

ANDRADE, G. V. M. Políticas habitacionais brasileiras: uma avaliação do programa Minha Casa, Minha Vida em suas duas edições. Trabalho de Conclusão (Graduação em Engenharia de Produção). Escola Politécnica da Universidade Federal do Rio de Janeiro. Rio de Janeiro, 2012.

ARETCHE, M. T. da S. Estado federativo e políticas sociais: determinantes da descentralização. 3. ed. Rio de Janeiro: Revan; São Paulo: FAPESP, 2011.

ARVATE, P. R.; BIDERMAN, C. Economia do Setor Público. Rio de Janeiro: Elsevier, 2004

BALTRUSIS, N. Transformações no modo de morar nas metrópoles contemporâneas: novos discursos, velhos problemas. Cadernos CRH, Salvador, v. 23, n. 59, p. 235-253, 2010. 
BARBOSA, I. S. O Estado a produção habitacional pública. Dissertação (Mestrado em Ciência Política). Faculdade de Filosofia, Letras e Ciências Humanas da Universidade de São Paulo. São Paulo, 2008.

BORGES, J. M. Políticas habitacionais, condições de moradia, identidade e subjetividade no programa Minha Casa, Minha Vida em Águas Lindas de Goiás. Dissertação (Mestrado em Geografia). Departamento de Geografia da Universidade de Brasília. Brasília, 2013.

CIRNE, J. R. M. Direito à moradia. Trabalho de Conclusão (Graduação em Direito). Universidade Federal do Rio Grande do Sul. Porto Alegre, 2011.

COSTA, L. P. da. Habitação e cidadania. A vila operária do IAPI: Porto Alegre 1940/1950. Dissertação (Mestrado em Ciência Política). Instituto de Filosofia e Ciências Humanas da Universidade Federal do Rio Grande do Sul. Porto Alegre, 2009.

DIAS, E. C. Do plano Real ao programa Minha Casa, Minha Vida: negócios, votos e reforma na habitação. Dissertação (Mestrado em Ciência Política). Faculdade de Filosofia, Letras e Ciências Humanas da Universidade de São Paulo. São Paulo, 2012.

DRUM, C. L. Déficit habitacional e impactos econômicos do programa Minha Casa, Minha Vida no Rio Grande do Sul. Dissertação (Mestrado em Economia do Desenvolvimento). Faculdade de Administração, Contabilidade e Economia da PUC-RS. Porto Alegre, 2010.

DUTRA, W. Z. Entre a produção habitacional estatal e as moradias precárias: uma análise da popularização da casa própria no Brasil. Perspectivas em Políticas Públicas, Belo Horizonte, v. VI, n. 11, p. 131-154, 2013.

FERNANDES, E. Estatuto da Cidade, mais de 10 anos depois: razão e descrença, ou razão e otimismo. Revista UFMG, Belo Horizonte, v. 20, n. 1, p. 212-233, 2013.

FERREIRA, A. R. Programas de combate ao déficit habitacional brasileiro. Trabalho de Conclusão (Graduação em Ciências Econômicas). Universidade Federal do Rio Grande do Sul. Porto Alegre, 2009.

FORAGI, R. Uma análise do programa Minha Casa, Minha Vida. Trabalho de Conclusão (Graduação em Ciências Econômicas). Universidade Federal do Rio Grande do Sul. Porto Alegre, 2012.

FUNDAÇÃO JOÃO PINHEIRO. Centro de Estudos Políticos e Sociais. Déficit Habitacional no Brasil. Belo Horizonte, 1995.

FUNDAÇÃO JOÃO PINHEIRO. Centro de Estatística e Informações. Déficit Habitacional no Brasil 2005. Belo Horizonte, 2006.

Déficit Habitacional do Brasil 2008. Belo Horizonte, 2010.

Déficit Habitacional do Brasil 2012. Belo Horizonte, 2014.

GIAMBIAGI, F.; ALÉM, A. C. Finanças públicas: teoria e prática no Brasil. 4. ed. Rio de Janeiro: Elsevier, 2011.

HOWLETT, M.; RAMESCH, M.; PERL, A. Política Pública: seus ciclos e subsistemas. Rio de Janeiro: Elsevier, 2013.

LANNOY, C. P. de. O descompasso das políticas públicas para solução do déficit habitacional. Dissertação (Mestrado em Arquitetura e Urbanismo). Universidade de Brasília. Brasília, 2006.

LARRATEA, M. G. Representações sociais, atores e interesses: a formação das políticas públicas em habitação no Rio Grande do Sul (1999-2002). Dissertação (Mestrado em Ciência Política). Instituto de Filosofia e Ciências Humanas da Universidade Federal do Rio Grande do Sul. Porto Alegre, 2004. 
MILANO, J. Z. Um lugar para chamar de seu? O programa Minha Casa, Minha Vida e a ideologia da casa própria. Dissertação (Mestrado em Planejamento Urbano e Regional). Faculdade de Arquitetura da Universidade Federal do Rio Grande do Sul. Porto Alegre, 2013.

OLIVEIRA, C. T. T. de. A implementação de políticas públicas habitacionais: o caso do Programa de Subsidio à Habitação de Interesse Social no Rio Grande do Sul. Universidade Federal do Rio Grande do Sul. Porto Alegre, 2011.

PROCOPIUCK, M. Políticas públicas e fundamentos da administração pública: análise e avaliação, governança e redes de políticas, administração judiciária. São Paulo: Atlas, 2013.

QUEIROZ, A. B. A economia da habitação social no desenvolvimento socioeconômico brasileiro: o caso do programa Minha Casa, Minha Vida. Trabalho de Conclusão (Graduação em Ciências Econômicas). Universidade Federal do Rio Grande do Sul. Porto Alegre, 2012.

REGERT, R. M. Análise da situação habitacional da população de baixa renda e o problema da exclusão social no município de Novo Hamburgo - RS. Dissertação (Mestrado em Desenvolvimento Regional). Universidade de Santa Cruz do Sul. Santa Cruz do Sul, 2010.

SCHREINER, E. A operacionalização do programa Minha Casa, Minha Vida: residencial Duque de Caxias. Trabalho de Conclusão (Especialização em Gestão Pública). Universidade Federal do Rio Grande do Sul. Porto Alegre, 2012.

SCHWANTES, L. Duplicação da Avenida Tronco (Porto Alegre-RS): déficit democrático na formulação e na implementação da política pública. Trabalho de Conclusão (Graduação em Administração). Escola de Administração da Universidade Federal do Rio Grande do Sul. Porto Alegre, 2013.

SECRETARIA DE HABITAÇÃO E SANEAMENTO DO RS. Disponível em:< http://www.sehabs.rs.gov.br > Acesso em 15 de abril de 2015.

SECREATARIA DE PLANEJAMENTO, GESTÃO E PARTICIPAÇÃO CIDADÃ DO RS. Disponível em:< http://www.seplag.rs.gov.br > Acesso em 15 de abril de 2015.

SILVA, J. M. M. N. Os interesses em torno da política de habitação social no Brasil: a autogestão no programa Crédito Solidário. Dissertação (Mestrado em Planejamento Urbano e Regional). Universidade Federal do Rio de Janeiro. Rio de Janeiro, 2009.

TRIANA FILHO, A. Habitação popular no Brasil: análise do modelo operacional de financiamento pelas agências oficiais. Dissertação (Mestrado em Arquitetura e Urbanismo). Universidade de Brasília. Brasília, 2006. 